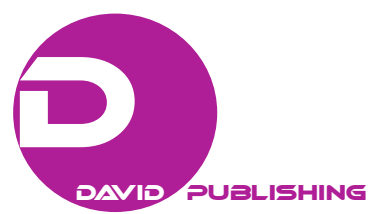

\title{
Can Quality of Content Be a Differentiator for Broadcast Programs? A Case Study in Japan
}

\author{
Azusa Tanada \\ Freelance, Toyama, Japan \\ Isamu Okada \\ Soka University, Tokyo, Japan
}

\begin{abstract}
This paper discusses the idea that the industry can have a differentiator of program quality by encouraging the activities of the Broadcasting Ethics \& Program Improvement Organization (BPO) in Japan. The BPO, a worldwide independent organization, has a mission of a breakwater against state power, and thus can be regarded as a kind of media accountability system, as proposed by Claude-Jean Bertrand. We review some controversial affairs in the TV industry and discuss BPO's activities aimed preventing "yellow journalism" and improving the quality of programming. High-quality content may be a differentiator for viewers faced with a choice of media, and thus, we focus on BPO and its role as a differentiator of the Japanese TV industry among the other, especially, Internet media. We also propose four ideas in response of critiques of BPO. Those are to strengthen transparency of governance of BPO, to improve the conformity of the TV industry to BPO's assessments of it, to establish a new committee to examine the whole concept of journalism, and to introduce a new certification institution to guarantee quality.
\end{abstract}

Keywords: TV industry, media accountability systems, TV journalism, BPO (Broadcasting Ethics \& Program Improvement Organization)

\section{Introduction}

The ad rates of television exceeded those of newspapers in Japan in 1975. On the other hand, the ad rates of the Internet are expected to exceed those of television in 2020 (Dentsu, 2015). This forecast is not only a numerical comparison of ad rates, but also indicates that the TV industry may suffer the same fate as newspapers, which is to become traditional media (Chaffee \& Metzger, 2001). TV broadcasting in Japan, which started in 1953, went digital in 1994. It has been afforded a special position even in an era of multiple media by the Japanese Broadcast Law, which certifies it as having a special social influence, and thus, broadcasters need to be issued licenses by the state. These licenses, however, place two big restrictions on broadcasters.

The first restriction is Article 4 of the law, which requires that broadcasters must submit only politically neutral newsreports. This neutrality principle is necessary because of a broadcaster's social responsibility of satisfying the people's right to know; that is, they cannot only focus on the points they consider most important

Azusa Tanada, Freelance.

Isamu Okada, Ph.D., Faculty of Business Administration, Soka University. 
in a news story. For example, a report that criticizes the power of the government must also report opposite opinions. As a result, broadcasters cannot sufficiently play the role of a watch dog.

The second restriction is that programs can easily be "yellow", in the sense of yellow journalism, because, except for NHK (Nippon Housou Kyoukai; its official name in English is Japan Broadcasting Corporation) broadcasters are commercial enterprises that favor variety entertainment and TV gossip shows, just as they do in other developed countries. An observation of this situation that became well known in Japan was that of Souichi Ooyawho said in 1956 "IchiokuSouHakuchika" (all Japanese are idiots); a similar sentiment was later expressed by Federal Communications Commission chairperson Newton N. Minow in 1961 that TV in the US was "a vast wasteland". The issue of this yellowing also makes a good excuse for interventions in the political power.

In order to respond these problems, NHK and the Japan Commercial Broadcasters Association (JBA) jointly established the Broadcasting Ethics \& Program Improvement Organization (BPO) as an independent worldwide body in 2003; as of 2015, its affiliated companies numbered 206. Its goal is officially defined as "to improve the quality of broadcasting and promote higher ethical standards while ensuring freedom of speech and expression" (BPO, 2015a).

BPO consists of three committees on ethics, human rights, and juveniles. Each committee investigates complaints and opinions from viewers and submits fiats to the affiliated companies. BPO also promotes itself in order to enhance viewers' awareness of its activities. As a result, the number of complaints and opinions from the viewers has been grown from 9,671 in 2005 to 16,993 in 2007, and 19,208 in 2011 (BPO, 2015a).

This organization actively tries to improve the quality of TV program content as well as to act as a breakwater against state power. In this paper, we emphasize that this new role in working to improve quality has an important function in the TV industry. Now, citizens of any sort can send information through the Internet. High-quality content may be a differentiator for viewers to choose between the growing variety of media. To discuss this point, we will deal with BPO and its role as a differentiator for the Japanese TV industry among other, especially Internet, media.

In Section two, we will give an overview of the Japanese TV industry and the background and objective of the BPO as a breakwater against statepower. Section three describe show BPO's activities have improved the quality of programs made by the TV stations. In Section four, we propose a number of responses to typical critiques of BPO. Section five concludes our discussion.

\section{BPO as a Breakwater Against Public Power}

In this section, we describe the broadcasting business world as envisioned by the Japanese Broadcast Law and the background to establishing BPO. In 1952, the year of the restoration of Japan's sovereignty after the Pacific War, the Yoshida cabinet uncompromisingly enacted the Broadcast Law that put the broadcasting business under the complete control of the government bureaucracy. This radio wave law ordains that broadcasters must obtain approval and a license from the Ministry of Internal Affairs and Communications (MIC) every five years. Although the purpose of the periodic reapproval and relicensing is to ensure that the business has maintained appropriate facilities for broadcasting, it is construable that the government can use these instruments to intervene in other affairs of the broadcaster.

The spread of the Internet cannot change the situation that broadcasting has been left in regarding control by a public power. When the Internet began providing content in 2006, the government embarked on are view 
of the laws regulating communications and broadcasting (Toyoshima, 2010). However, no action was taken because keeping a balance between the freedom of expression put forward in Article 21 of the Constitution and the restrictions derived from the use of the limited radio air resource is difficult. The limited air resource cannot be a grounds for approval and licenses by the technological innovation, and thus, according to the verdict of MIC, businesses are divided by two groups in terms of the extent of their "special social impact" (MIC, 2009). One group conforms to the regulations of Digital Terrestrial Television Broadcasting (DTTB), and the other group has a looser set of regulation for broadcasting and which supposes new media including Internet media. However, the borderline between these groups is as yet ambiguous. As a consequence, only the communications infrastructure is regulated by the law and there is no basic law on media services and media communications using the infrastructure. That is to say, in Japan, broadcasting companies are of two types: those regulated by the Broadcast Law and the new media service companies without regulations by the law.

DTTB regulates broadcasting in the point of not only approval and licensing; it is also one's duty to set up a deliberative organ for the programs. Although all TV stations of the DTTB, therefore, have had such the organizations, they have been mostly ineffective because they are not proactive. A state who would like to control the media upon observing that the organizations do not work promptly and proactively could intervene in the broadcasting business world. The first opportunity for the Japanese government to do so was the so-called "TsubakiJiken" incident (Shimizu, 1995) ${ }^{1}$. This affair involved TV Asahi that was suspected of a politically biased broadcast in 1993. After executing the Broadcast Law, the government officially ripped up alicense of the broadcaster for the first time. The second affair concerned another broadcast by TV Asahi on dioxin in 1999 (Yamaguchi, 2010). The executive head and chief of broadcasting were summoned to parliament and the newscaster was made to apologize for the broadcast.

Broadcasting businesses, prompted by these two affairs in which the state intervened, recognized the need for an organization that could take the necessary steps and give guidance before the workings of the state intervened. This motivation led to the establishment in 2003 of the BPO as a breakwater against statepower. This historical background is why its mission is not only to improve the quality of TV programs but to prevent the state from intervening in the affairs of broadcasters. A comparison of the role of the BPO to that of the previous deliberative organs shows that it is inter-organ.

The trigger that caused BPO to expand its role is was the affair related to a report describing a fake natto diet broadcasted by Kansai Telecasting Corporation (KTC) on January 7, 2007 (Kobayashi, 2007); the program had an average viewing rate of $15 \%$. In the broadcast, important data that supported the effectiveness of the natto diet was faked. The scandal of such a popular program having a faulty piece of investigative journalism had a strong impact on society, and viewers' distrust of broadcasters deepened as a result of it and a series of scandals that followed.

On the one hand, BPO dealt with the affair and announced two recommendations (One published on January 29, other on February 7). Its recommendations criticized not only KTC but also the whole broadcasting business. On the other hand, MIC simultaneously requested KTC to submit a report and signaled its intention to strengthen the surveillance and oversight of the broadcaster. On February 7, it announced to NHK and private broadcasting companies and embarked a review for a revision to the law. BPO was alarmed by these moves of the government and gave voice to a concern about it intervening in broadcasting.

\footnotetext{
${ }^{1}$ Shimizu, H. (1995). Records of a committee on communications of the Lower House No. 128, Vol. 2, p. 2.
} 
The business world had to take measures against the affair, while the majority of viewers supported intervention by the state. As a result, JBA decided to review KTC on February 15 and unanimously decided to remove it from its membership on April 19. Simultaneously, it sought to strengthen BPO's authority in order to prevent the state from intervening. They publicized the fiats by the BPO, reported to its deliberative organs, and made public its plans to prevent a recurrence of such problems. BPO showed an intention of preventing such interventions by proactively announcing the results of their investigations at press interviews. According to the Tokyo Newspaper on February 16, 2007, this agreement was aimed as a confidence-building measure for viewers and for restraining a statement on strengthening its administration and surveillance by demonstrating that the broadcasters could haul themselves up by their own bootstraps. As a consequence, the authority of the BPO was strengthened.

\section{Can BPO Improve the Quality of Content?}

A comparison of business models shows that the TV media and newcomers including Internet media are competitors because they essentially provide similar services despite that their channels, including their transmission services and equipment, are different. This similarity weighs against the TV industry because of its huge infrastructure and related costs (Nyarko, 2013). In fact, the ad rates of the TV industry in Japan continue to decline as do audience rates (Dentsu, 2012) ${ }^{2}$.

However, as mentioned in the introduction, guaranteeing the quality of content provided by broadcasters can be an advantage over new media from the viewpoint of the business model. Although the original mission of the BPO is as a breakwater against state power, its activities also promote quality. In this section, we will exemplify this point through several case studies.

\section{Strengthening of the Role of the BPO in Regard to Improving the Quality of Content}

While the role of the BPO has been strengthened as described in Section two, we must test whether it effectively works through an examination of actual cases in which it has acted. In this subsection, we deal with two cases of news programs broadcasted in 2008 and 2009. These two cases clarify that a strengthened BPO has had an effect on the concerned broadcasters.

The first case dealt with the "ShinsoHoudouBankisha" news program broadcasted by NTV (Nippon Television) on November 23, 2008 (BPO, 2009). Although the news item dealt with a case of raising off-the-book funds in a public civic engineering project, the core component of the report featuring the testimony of interviewees was debunked. As a consequence, the affirmant who gave the false testimony was arrested and the chief executive of NTV resigned.

In order to explore the reason why the erroneous report emerged, the BPO instructed NTV to recognize its right to conduct an investigation. As a result, BPO urged NTV to make a verification program. NTV took this to heart seriously and took steps to improve its news gathering. Mr. Seiichoro Ujiie, the President of NTV, said "BPO is working properly. Although NTV reported absolutely false information, we have complied with the adjuration submitted by BPO to the extent possible" (Asahi News Paper, 2009) ${ }^{3}$. He pointed out that the leadership exercised by BPO had been proper.

The second example involves the news program, "Joho 7 days News Caster" of TBS (Tokyo Broadcasting System Television) broadcasted on April 11, 2009. While the news reported on government duplicity, it

\footnotetext{
${ }^{2}$ Dentsu, S. (2012). A news release on February 23, 2012 (written in Japanese).

3 Asahi News Paper. (2009). A news article on Asahi News Paper at October 20, 2009.
} 
featured an untruthful choreographed scene that became an object of public concern. TBS apologized for airing the report two weeks later.

BPO investigated the case and finally passed over discussing it because in its view TBS had already figured out what was behind the problem, took preventive steps, and cracked down on those involved. However, MIC severely reprimanded TBS as it had fallen a foul of the Broadcast Law. BPO protested the reprimand, and this protest accordingly succeeded in winning the confidence of broadcasters that BPO was indeed acting impartially.

\section{BPO's Activities Related to Quality Improvement}

While TV stations have attached high value to the fiats issued by BPO since 2007, it was observed that BPO had proactively recommended for improving the quality of the content provided by TV stations in addition to formulating responses to programs that had drawn criticism from society. Here, we consider the cases of two TV programs as evidence of BPO's new activities.

The first example deals with a variety program, "Geino BANG The Golden" of NTV broadcasted on May 4, 2012. Although the program featured sensational headlines at that time and repeatedly announced that the key person would appear on the program, that person did not appear. As a consequence, NTV received a flood of protests, and this prompted BPO to investigate what had happened.

According to an investigation of the Broadcasting Ethics Committee of BPO, the program featured such senseless content even though NTV had failed to negotiate the appearance of the said person more than a month before. The President of the committee criticized the program as a double-cross for the audience. He said "NTV treated the viewing audience as a tool for capturing ratings. It fundamentally lacked love for itsviewers" (Tokyo News Paper, 2012) $)^{4}$.

The second case related to a variety program "AriehenSekai" of TV Tokyo broadcasted on January 25, 2011. A village mayor sent a letter of request for amendment and apology to TV Tokyo because the broadcaster had made a report on the village that was not based on fact.

Although TV Tokyo submitted a report that concluded human error, the Ethics committee held a hearing and denied the validity of the report. The final fiat of the BPO mentioned that "when producers and performers make a variety program that deals with Fred Bloggs as a material, the most important point for them is love for those who become targets" (BPO, 2011).

The interesting aspect of these two cases is that BPO used the word "love" in the fiats. This is symbolic in that BPO does not formally discuss issues so much as responses to complaints by viewers but rather supposes that it knows producers' attitudes to their products and their quality. While they were solicitous of the producers fears that their programs were judged on ethical grounds, they made an appeal to them, while at the same time admonishing that the independence and the autonomy of broadcasting depends on their being careful about their productive activities. We emphasize that such enthusiasm signifies BPO's awareness of its new mission to proactively make recommendations that improve the quality of the TV programs.

\section{BPO's Approach to the TV Business as Viewed Through its Recommendations}

The final case that we will examine is that of BPO's self-imposed role as a leader in improving the quality of TV programs. BPO originally played a passive role in which it examined TV programs criticized by viewers in order to uphold their basic human rights. In that way, BPO did not need to bring up a matter by itself. However, BPO had to face the fact that variety programs occupied the greater part of the viewer complaints,

\footnotetext{
${ }^{4}$ Tokyo News Paper. (2012). A news article on Tokyo News Paper at October 5, 2012.
} 
and this situation put pressure on BPO to respond to them in particular. As a consequence, BPO issued a general statement on variety programs as a whole and positively took a step toward its next mission.

On November 17, 2009, BPO published an unusual fiat, 45 pages long, titled the seventh fiat of the Broadcast and Human Rights/Other Related Rights Committee, a Comment on the Recent Variety Programs on $T V$. The official report adopted not only a provocative style of writing but also included manga-style illustrations in order to raise the issues of the poor quality of variety programs and their ethics concurrently. In so doing, they hoped that program producers would realize that they had given the state an opportunity to intervene by virtue of the fact that variety programs occupied $70 \%$ of the notes, serious attentions, and admonishments issued by the state.

In a quick response to the fiat, on November 19, JBA called for its affiliated companies to undertake more discussions on their variety programs. Moreover, JBA shared some of the views of BPO and organized a symposium to gether with 50 producers of variety programs in the coming March.

This case suggests that BPO tried to work with the whole broadcasting business not only for preventing the state from intervening but by recommending a would-be ideal for variety programs. We speculate that BPO recognized that the producers had not sufficiently been aware of the situation because they were not aware of the many complaints it had received. BPO strategically had an axe to grind for warning the producers in a time of a relative rise in position since 2007. That is why the fiat asked broadcasters to deal with some matters voluntarily.

\section{Proposals in Response to Critiques of BPO}

Above, we reviewed examples of BPO's extended role in which it appeared to be a differentiator of broadcasting from new media. In this section, we propose institutional improvements in response to important critiques and to strengthen competitive advantage.

There are three major critiques of BPO. Although BPO has received much praise, e.g., one of its founders said "(it is) one of the most excellent organizations for monitoring programs in the world" (Hirose, 2007) ${ }^{5}$, it has also received persistent criticisms. By outlining measures that could be taken in response to those criticisms, we can give a new direction to BPO. We also propose that it should establish a new institution to enhance its functions as a differentiator between media. In so doing, we will discuss the possibility of BPO becoming a source of competitive advantage for the broadcasting business.

\section{Strengthening Transparency of Governance of BPO}

One of the main critiques is its selection rules for committee members and criteria for examination. Okumura (2010) put his finger on three problems while at the same time appreciating that "the insights, experiences, abilities of investigation of every committee of BPO are excellent and I cannot imagine building a better organization than that of BPO in Japan". The first problem is that the selection of referees does not ensure a sufficient level of fairness; the second is that the criteria for selecting what BPO deals with is fuzzy; the third is that BPO needs more objectivity about its criteria.

For BPO to be an important organization in the TV business world, it must ensure transparency of its governance. The selection rules for committee members could be laid down in terms of areas of expertise and strengths. The criteria for examination could also be defined as a series of conditions such as problem domain,

\footnotetext{
${ }^{5}$ Hirose, M. (2007). A speech as President of JBA in a committee of the House of Representatives on June 20, 2007.
} 
social influence, and expectations for improvement. Making such efforts towards transparency would give BPO an air of authority, and broadcasters would more likely be inclined to follow the fiats issued by it.

\section{Improving Conformity to Recommendations}

The agreement between NHK, JBA, and BPO does not have the force of law, so there have been some cases in which TV stations ignored the recommendations of BPO. For example, in regard to a program dealing with the questions as to who holds responsibility for World War II broadcast on NHK on January 30, 2001, BPO submitted fiats twice, once in 2003 and once in 2009. However, NHK ignored the fiats and criticized the BPO. We believe it necessary that NHK and JBA conform to BPO recommendations.

This situation should be improved by changing the stations' internal regulations and making the position of BPO clear to all concerned. However, we believe that BPO must not have the force of law because it should remain an independent organization that acts as a go between with the government (MIC). BPO should act as a messenger of and to broadcasters, so that it can fulfill its social responsibility and advocate the people's right to know.

Who and what should conform to BPO recommendations? The previous section covered case studies showing that the BPO has a new function that the state does not have; BPO is a third independent deliberative organ that shows enthusiasm for the development of the TV business. The BPO's recommendations are like most helpful advice that may be difficult to listen to. This is because it takes the long-term, often historical, view, whereas broadcasters often take short-term views. So far as the BPO has enthusiasm, it is a salient feature that new media do not have. The difference between broadcasting media and new media is in whether they have a deliberation organ or not. BPO not only promotes quality of programs but also is interested in the whole field of DTTB. That is why recognition that BPO recommendations can be a differentiator of quality is important. People in the TV business should take BPO more seriously as it is a third independent deliberative organ, not for new media, but for broadcasting in Japan.

The direction to improve BPO also bears a new noticeable issue like an overdrive. However, BPO should not be so over-empowered that its fiats could bind the affiliated companies. As mentioned above, the powers of BPO must be clarified. Moreover, we propose that the referees must be acceptable to the affiliated members.

\section{Proposal to Establish a New Committee on Journalism}

Another critique is that BPO runs the risk of intimidating TV stations as it becomes more influential. Okumura (2010) pointed out the double punishment meted out by BPO and the state. The government through MIC has issued administrative advice to broadcasters every year except two since 2007, during which term the role of the BPO was strengthened. Needless to say, the BPO and the MIC play different roles. The right of supervision of DTTB including the right of allocating the electromagnetic spectrum in Japan belongs to the MIC, whereas BPO, as a breakwater against the intervention by the state, has the important mission of guaranteeing freedom of expression. However, broadcasters may feel that they get the same sort of heavy handed treatment whether by state regulation or by BPO recommendation. In recognition of this possibility, BPO sent a fiat to all concerned titled "moving onward without be intimidating" (BPO, 2015b). The fiat mentioned "our concern is when we decide to conduct an investigation or make a recommendation that we should act in way that does not intimidate those in the broadcasting field".

Lack of understanding of the intention behind establishing BPO is the cause of the perception of intimidation. As such, BPO may appear to be a burden on TV stations. If so, the DTTB cannot long survive 
because it has huge costs, as Nyarko (2013) pointed out. Thus, we believe the roles of BPO must be redefined from the viewpoint that it exists for raising the consciousness about the differences of TV from the other, especially Internet media. It costs much more to make TV programs than to make Internet media, so much so broadcasting television cannot compete with Internet media in a price war. Differentiating broadcasting from other media should therefore emphasize the quality of programming. Improving programming is one of BPO's reasons for existence, yet if TV stations feel intimidated by it, it would be a pathological problem from the viewpoint of freedom of expression and the true meaning of journalism.

We propose that the mission of the BPO should be expanded and a new committee established to examine the whole state of journalism. Here, we must deal with the risk of double punishment that TV stations feel is harmful to freedom of expression and healthy journalism. If BPO is just grievance airing mechanism, it would be difficult for broadcasters to change their minds on the double punishment issue. As mentioned in the previous section, the BPO has made recommendations in regard to the future of variety programs aimed at improving their quality. Our proposal is to set up a new independent committee.

The new committee would need to autonomously submit recommendations in order for industry participants to ensure that their work befits their position as leaders in journalism and that they take pride in being journalists. That is to say, the committee should be able to freely discuss whatever topic the members want. At the same, the committee would proactively deal with broadcasts unduely influenced by the state's pressure. Such a Journalism Committee would dramatically change the mission of BPO. In particular, it should have two tasks. One is to deal with complaints from viewers; the other is to give advice and suggestions to TV journalists make sure their positions within their broadcasting organizations. If BPO could help to keep freedom of speech, TV stations would no longer be under the threat of double punishment. As a watch dog, BPO would help free the TV industry from the danger of atrophy.

\section{Introducing a New Certification Institution for Guaranteeing Program Quality}

In order to emphasize the competitive advantage that BPO could give broadcasters against the other, especially Internet, media, we propose a new certification institution for ensuring the quality of TV programs. Although the previous three items of this section are responses to the main critiques of BPO, they do not necessarily ensure that quality is a differentiator. The following idea originates from the traditional media of movies.

EIRIN (the Film Classification and Rating Committee) was established as an independent non-governmental organization in 1956 in Japan in order to limit censorship by the state. As in the case of other such organizations in many developed countries, EIRIN has a labeling system that divides theatrical films and other related content into four categories. A work that has passed a screening is labeled with an EIRIN mark. EIRIN labels about 600 works per year, and examination certificate fees cover almost all of its administrative costs.

Would the labeling system used in the movie field work in the TV field? Japanese TV already has a rating system. It was established in 1960 by Nielsen Company of America and was continued after Nielsen left Japan by Video Research Ltd, in the form of a rating survey of Japanese TV programs. Here, we should take care to ensure that a TV rating system and labeling system administered by BPO is clearly distinguished.

The first point is that the labeling system in the movie field is different from a quality certification institution in the TV field. As well, the labeling system requires its criteria to be carefully discussed; the criteria 
of quality should be clearly defined. Of course, the institution proposed here cannot evaluate the general meaning of quality of content. At a minimum, though, we can cite three traits of high quality content: correctness, ethics, and respect for human rights. The new institution should check whether or not the target content includes incorrect descriptions, unethical issues, or forms of expression against basic human rights.

The second difference is the quantity of objects. TV programs are produced in countless numbers and their types are various. Therefore, the targets may be restricted in type and in number in the beginning. Despite such a restricted range, however, we believe that certification would be a significant signal for not only viewers but also producers; it would provide a measure of common sense that the viewing rate lacks.

\section{Conclusion}

In this paper, we have kicked around questionof how BPO could be a differentiator of DTTB from new media by reviewing the background to its establishment, movements for strengthening its authority, describing measures in order to respond to some of its main critiques, and proposing a new institution.

In Section two, we dealt with the background to establishing BPO and reviewed its original mission. BPO was established as a third-party organization to prevent public authorities from intervening in broadcasting and had the aim of ensuring the freedom and independence of broadcasting and that broadcasters would act as organizations of the press. Although the Broadcast Law requires broadcasters to set up deliberative organs, they do not necessarily work as intended. The state managed to strengthen its power and intervene in the broadcast business especially after two affairs in 1993 and in 1999 broke out in which viewers also criticized those affairs. As a consequence, NHK and JBA jointly established BPO. The authority of BPO was strengthened through the resolution of an affair in 2007. NHK and JBA agreed to observe compliance rules including to publicize fiats issued by the BPO, to report to their deliberative organs, and to make public what their plans are to prevent recurrences of such problems in the future.

BPO's problem of consciousness raising is similar to the case of the USA after the publishing of "A Free and Responsible Press" by the Hutchins Commission (i.e., the Commission on Freedom of the Press) in 1947. Its discussion of the issue is first within the realm of social responsibility theory. Later, Claude-Jean Bertrand developed and promoted the concept of Media Accountability Systems (Bertrand, 2007), which he defined as "any non-governmental means of inducing media and journalists to respect the ethical rules set by the profession". He dealt with the issue how to let journalists and media audiences keep ethical values without any censorship by nations. BPO can be regarded as a kind of Media Accountability System.

In Section three, we described how BPO expanded its mission by through reaching out to the whole broadcasting world. We examined cases in which BPO actions and recommendations were supported by businesses and were perceived as effective. The new mission of the BPO can be accordingly regarded as giving a certain amount of guarantee to the quality of TV programs. BPO's original job is to receive viewers' complaints and to submit recommendations to broadcasters as part of a grievance airing mechanism, and thus, it acts as a passive and ex-post organization to expose inferior products. By contrast, its new job would ultimately be to check TV programs in advance to ensure their quality, and thus, it would be an active and ex-ante organization to make an organizational culture not produce inferior products. This approach to the organizational climate would be a differentiator of broadcasting from new media, which do not have a proactive control of program quality. This is a unique advantage because, as mentioned by Kiousis (2001), viewers' assessment of the credibility of a medium like TV generally decrease in a time of information overload. 
The expansion of its roles, however, could put pressure on part of the field. In this regard, Section four described the issues of double punishment and atrophy. Producers that claim innocence and expediency are doubtful as to their accountability, as pointed out by Bertrand (2007). We need to change their minds. To do so, we proposed a new committee to examine all aspects of journalism. This committee may strengthen the actual authority of the BPO. Section four also dealt with the issue of transparency of governance. The systemic reforms outlined therein would redefine BPO's relationship with the broadcasting business. However, multiple lines of effort may be needed before BPO can give a competitive advantage to DTTB and improve its chances of survival.

What should the new functions of BPO be? In Section four, we proposed a new certification institution for guaranteeing the quality of programming. Although our proposal is still rough-around-the-edges and remains a matter of debate, such a function would have a great impact on BPO and its circumambient society. Okumura (2010) mentioned that viewers have demanded that BPO exercise leadership in order to reinvent the broadcasting business. In this paper, we proposed a clarification of its governance, an expansion of its mission by setting up a new institution and committee, and improvement of conformity in order for BPO to be a source of competitive advantage for the broadcasting business.

\section{References}

Bertrand, C. J. (2007). Media accountability systems. French Press Institute, University of Paris. BPO. (2009). Commission fiat 6 “'An adjuration for NTV”. Retrieved from http://www.bpo.gr.jp/ BPO. (2011). Commission fiat 13 “An opinion for TV Tokyo”. Retrieved from http://www.bpo.gr.jp/ BPO. (2015a). The homepage of BPO. Retrieved from http://www.bpo.gr.jp/ BPO. (2015b). Commission fiat 21 “An opinion for TV Asahi”. Retrieved from http://www.bpo.gr.jp/

Chaffee, S. H., \& Metzger, M. J. (2001). The end of mass communication? Mass Communication and Society, 4(4), 365-379.

Dentsu, S. (2015). A research for information and media society. Diamond Publishing Co. Ltd.

Kiousis, S. (2001). Public trust or mistrust? Perceptions of media credibility in the information age. Mass Communication and Society, 4(4), 381-403.

Kobayashi, I. (2007). A warning of fabricated information contained in TV broadcast: A study on harmful social influences of a series of news broadcasts. Reports of Jin-ai University, 6, 99-118.

Ministry of Internal Affairs and Communications. (2009). A verdict No. 14 in 2008 on the whole concept of the integral law system on communications and broadcasting. Retrieved from http://www.soumu.go.jp/menu_news/s-news/02tsushin01_000024.html (written in Japanese)

Nyarko, I. K. (2013). Effects of electronic media advertising on rural banking in Ghana: A study of Unity Rural Bank Limited, Ho Ghana. Journal of Asian Business Strategy, 3(11), 315-329.

Okumura, N. (2010). Role and function of BPO: Government's supervision and control and freedom of speech in Japanese broadcast. Ritsumeikan Review of Industrial Society, 45(4), 1-29.

Toyoshima, M. (2010). A concept of communication and broadcasting and a possibility to change discipline of contents (Working Papers by Institute of Journalism, Media \& Communication Studies, Keio University, No. 60 , pp. 117-134).

Yamaguchi, H. (2010). An issue on the "News Station" broadcasting dioxin (Working Papers by Institute of Journalism, Media \& Communication Studies, Keio University, No. 60, pp. 155-165). 